\title{
ASSOCIATIONS BETWEEN AUSTRALIAN PSEUDOSCORPIONS AND ANTS
}

\author{
By Deborah C. Cole $^{1}$, Mark A. Elgar ${ }^{1}$, and Mark S. Harvey ${ }^{2}$
}

\begin{abstract}
The distribution of three species of pseudoscorpions, found under the bark of blue gum Eucalyptus globulus, is closely correlated with the presence of three species of ants. Marachernes bellus is never found on trees without Anonychomyrma sp. near foetens, and Protochelifer victorianus and Paraustrochernes victorianus are more commonly found on trees with Technomyrmex jocosus and/or Tapinoma minutum. The distribution of another pseudoscorpion, Conicochernes sp., is not influenced by the presence of these ants. Observations of the behavior of these pseudoscorpions indicate that at least some species may be specialist predators of ants.
\end{abstract}

\section{INTRODUCTION}

The nests of ants are host to an extraordinary diversity of insects and other arthropods, among the most common being mites and staphylinid beetles (e.g., Hölldobler and Wilson 1990). Numerous other species, that do not necessarily enter into the nests of ants, also form apparently close associations with ants. The relationships between these symbionts (sensu Kistner 1979) and their ant hosts appear to cover the entire spectrum of ecological associations (Kistner 1982, Hölldobler and Wilson 1990). Some are mutualistic (e.g., Pierce 1987), some parasitic (Hölldobler and Wilson 1990), while others, including many arachnids, are specialist predators (e.g., Elgar 1993).

Several pseudoscorpion species from at least six genera are thought to be myrmecophilous, although the nature of their relationships with ants has not been clarified. For example, Hölldobler

\footnotetext{
${ }^{1}$ Department of Zoology, University of Melbourne, Parkville, Victoria 3052, Australia.

2 Western Australian Museum, Francis Street, Perth, Western Australia 6000, Australia.

Manuscript received 2 August 1994.
} 
and Wilson (1990) report that the pseudoscorpions Pycnochernes eidmanni Beier (now Americhernes eidmanni (Beier); see Harvey 1991) and Syndeipnochernes camponoti Beier prey on small synoeketes present in the debris chambers of their hosts Atta and Camponotus. The synoeketes are ignored by the ants, perhaps because of their neutral odor, slow movement, small size, peculiar shape, or a combination of these features (Kistner 1979). Other pseudoscorpions are predators of the ants; for example, Paratemnoides elongatus capture workers of Cephalotes atratus, which are 30 times their own mass. These pseudoscorpions forage cooperatively, which may enable them to capture their larger prey (Zeh and Zeh 1990). Three other genera of pseudoscorpions, Marachernes, Myrmochernes and Xenochernes may also be myrmecophilous (Mahnert 1985, Harvey 1992).

The biology of Australian pseudoscorpions is poorly understood (e.g., Harvey 1988), and despite their prevalence in the Australian fauna, there have been remarkably few studies of their ecology (Weygoldt 1969, Harvey 1988). Nevertheless, anecdotal evidence indicates that at least one Australian pseudoscorpion, Marachernes bellus Harvey, is associated with workers of the ant Anonychomyrma (= Iridomyrmex, see Shattuck 1992) sp. near foetans Clark (Harvey 1992). This study describes the ecological associations between ants and several pseudoscorpion species from southern Victoria, Australia.

\section{MethodS}

The study site is dry sclerophyl forest located adjacent to the Otway Range State Forest, near the estuary of Separation Creek, Victoria, Australia. The trunks of individual blue gums Eucalyptus globulus globulus were censused up to a height of 1.8 meters from January through March 1994. A tree was chosen arbitrarily, and the following data were recorded: the species and number of any ants present, \% cover of simple and complex bark types, \% overhead cover, $\%$ undergrowth, and girth at approximately $1.4 \mathrm{~m}$. Where a tree had two or more trunks, the girth of each trunk was summed. The tree was then inspected for the presence of pseudoscorpions by removing all of the loose bark up to a height of approximately 1.8 meters. Each tree was searched for 30 minutes by two people. Pseudoscorpions were identified either in the field or collected for 
later identification. Ants were collected for later identification, and voucher specimens of both the pseudoscorpions and ants have been deposited in the Western Australian Museum and the Australian National Insect Collection respectively.

For the analysis, ant numbers were assigned to one of three categories, according to the number of ants of each species that were observed in five minutes: few (less than five workers), some (between 6 and 20 workers) or many (greater than 20 workers). Most trees were also inspected for ants during the previous evening. If the number of ants differed between the nocturnal and diurnal inspection, the greatest estimate of ant numbers was chosen, except in the case of 'none' and 'many', where 'few' was chosen. The numbers of pseudoscorpion offspring attached or adjacent to their presumed mothers were not included in the statistical analysis because they were not independent data values.

\section{RESULTS AND Discussion}

A total of 34 trees, that ranged in girth from 0.40 to $4.99 \mathrm{~m}$ with a mean of $1.64 \mathrm{~m}$, was censused. The percentage cover of complex bark on trees ranged from 10 to 100 percent, with a mean of $60.5 \%$. Four taxa of pseudoscorpions were found under the bark of E. globulus: Conicochernes sp., Marachernes bellus, Protochelifer victorianus Beier, and Paraustrochernes victorianus Beier. They are morphologically quite similar, with adult body lengths of 4.0 $\mathrm{mm}$ for Conicochernes sp., 2.7-3.3 $\mathrm{mm}$ for $M$. bellus, 2.7-3.0 mm for Pr. victorianus and 3.0-4.0 $\mathrm{mm}$ for Pa. victorianus.

There were differences in the abundance of the pseudoscorpions found on the 34 trees that were sampled: the most abundant were $\mathrm{Pa}$. victorianus and Conicochernes, with $1.3(\mathrm{SD}=1.9)$ and 1.3 $(\mathrm{SD}=2.8)$ individuals per tree respectively. Pr. victorianus and $M$. bellus were less abundant, with $0.3(\mathrm{SD}=1.9)$ and $0.2(\mathrm{SD}=2.8)$ individuals per tree respectively.

The ants present on the trees were dominated by three species: Anonychomyrma sp. near foetans, Tapinoma minutum Mayr, and Technomyrmex jocosus Forel. A few other species of ants were seen occasionally and in very low numbers, and hence their abundance was not recorded.

The presence of the three pseudoscorpion species on trees was significantly associated with the presence of ants (Table 1). M. bellus 
was only found on trees with $A$. sp. near foetans, as originally suggested by Harvey (1992). This association between M. bellus and $A$. sp. near foetans appears to be obligate, since $M$. bellus was never found on trees without ants. The survey also revealed two other possibly myrmecophilous pseudoscorpions; both Pr. victorianus and Pa. victorianus were more likely to be found on trees with $T$ e. jocosus and/or Ta. minutum than trees without these ants.

The abundance of two pseudoscorpions, Pr. victorianus and $P a$. victorianus, was significantly associated with the abundance of $T e$. jocosus and/or Ta. minutum (Fig. 1). An analysis of covariance, with the main factor comprising three categories of ant abundance and tree girth as the covariate, revealed that the numbers of both $P a$. victorianus and $P r$. victorianus per tree were significantly explained by the number of these ants (Pr. victorianus: $\mathrm{F}_{2,30}=$ $3.62, \mathrm{p}=0.04 ;$ Pa. victorianus: $\mathrm{F}_{2,30}=5.96, \mathrm{p}=0.01$ ) but not tree girth (Pr. victorianus: $\mathrm{F}_{1,30}=0.122$, ns; Pa. victorianus: $\mathrm{F}_{1,30}=$ $0.187, \mathrm{~ns})$. Interestingly, the numbers of $P a$. victorianus per tree increased linearly with ant abundance, but Pr. victorianus was most abundant on trees with between 5 and 20 ants.

The abundance of $M$. bellus was not significantly affected by the abundance of $A$. sp. near foetans $\left(\mathrm{F}_{2,30}=1.517, \mathrm{p}=0.236\right)$, but was influenced by tree girth $\left(\mathrm{F}_{1,30}=6.844, \mathrm{p}=0.014\right)$. The apparent dependence of $M$. bellus on the presence of $A$. sp. near foetens is unlikely to be due to a relationship between the abundance of $A$. sp. near foetens and the girth of trees because there was no difference in the girth of trees with or without ants $(t=1.27$ : d.f $=32$ : $p=0.21)$. There were no other significant correlations between the numbers of pseudoscorpions per tree and any of the tree or vegetation variables that we measured.

These distributional associations between the pseudoscorpions and ants suggest a direct relationship between the two taxa. However, patterns of this kind should be interpreted cautiously because the association may arise as a result of the presence or absence of a third party. For example, predators of pseudoscorpions may be effectively excluded by ants thereby providing an enemy-free space (e.g., Jeffries \& Lawton 1984). Alternatively, prey species of the pseudoscorpions may be obligate ant symbionts, or ants and pseudoscorpions may respond similarly to some other, unknown ecological factors. 
Table 1. The number of trees in which pseudoscorpions and ants were present.

\begin{tabular}{|c|c|c|c|c|}
\hline & \multicolumn{2}{|c|}{$\begin{array}{c}\text { Anonychomyrma sp. } \\
\text { near foetans }\end{array}$} & \multicolumn{2}{|c|}{$\begin{array}{l}\text { Ta. minutum and/or } \\
\text { Te. jocosus }\end{array}$} \\
\hline & Present & $\overline{\text { Absent }}$ & Present & $\overline{\text { Absent }}$ \\
\hline \multicolumn{5}{|l|}{ Protochelifer victorianus } \\
\hline Present & 4 & 5 & 6 & 3 \\
\hline Absent & 14 & 11 & 6 & 19 \\
\hline Fisher's exact probability & \multicolumn{2}{|c|}{0.70} & \multicolumn{2}{|c|}{0.04} \\
\hline \multicolumn{5}{|l|}{ Marachernes bellus } \\
\hline Present & 5 & 0 & 2 & 3 \\
\hline Absent & 13 & 16 & 10 & 19 \\
\hline Fisher's exact probability & \multicolumn{2}{|c|}{0.05} & \multicolumn{2}{|c|}{1.00} \\
\hline \multicolumn{5}{|l|}{ Paraustrochernes victorianus } \\
\hline Present & 11 & 7 & 10 & 2 \\
\hline Absent & 7 & 9 & 8 & 14 \\
\hline Fisher's exact probability & \multicolumn{2}{|c|}{0.49} & \multicolumn{2}{|c|}{0.01} \\
\hline \multicolumn{5}{|l|}{ Conicochernes sp. } \\
\hline Present & 9 & 4 & 3 & 10 \\
\hline Absent & 9 & 12 & 9 & 12 \\
\hline Fisher's exact probability & \multicolumn{2}{|c|}{0.17} & \multicolumn{2}{|c|}{0.29} \\
\hline
\end{tabular}

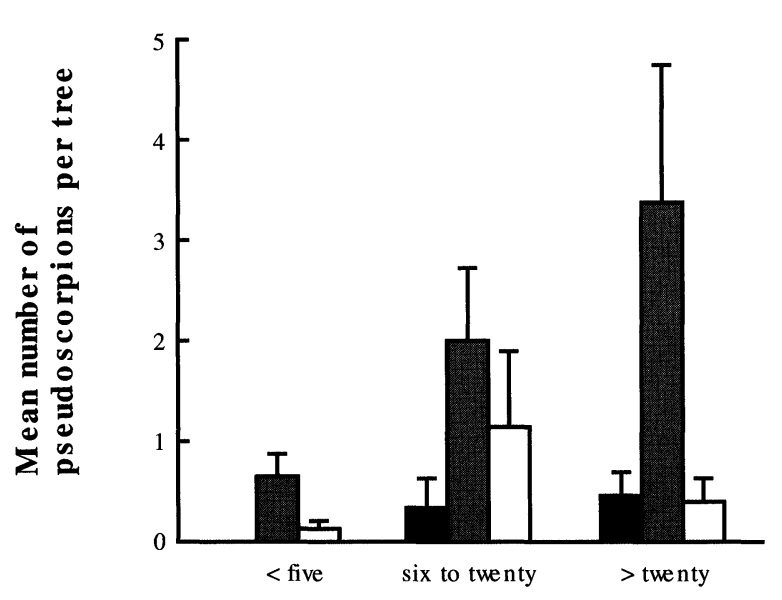

Marachernes

듬 Paraus trochernes

$\square$ Protochelifer

\section{Ant abundance}

Fig. 1. The relationship between pseudoscorpion and ant abundance on individual Eucalyptus globulus. Ant abundance refers to Anonychomyrma sp. near foetans for Marachernes bellus, and Tapinoma minutum and/or Technomyrmex jocosus for Paraustrochernes victorianus and Protochelifer victorianus. 
Although the number of $P a$. victorianus found on trees was positively correlated with the abundance of Te. jocosus and/or Ta. minutum, the association between these species is most likely facultative because Pa. victorianus also occurs on trees without ants. There are several reasons why $P a$. victorianus might benefit from associating with these ants. The presence of the ants may create a predator-free environment, and/or increase the abundance of trophobionts, potential prey items. Additionally, the behavior of the ants may directly benefit individual pseudoscorpions. Like ant larvae, newly emerged protonymphs are vulnerable to dessication and predation and thus may benefit from living in ant shelters. Protonymphs found with a female $P a$. victorianus were observed being carried by workers that may have been Te. jocosus or Ta. minutum. The workers carried the nymphs into a small hole in the trunk, but ignored the adult. Although these nymphs may have been prey of the ants, these observations raise the intriguing possibility that the chemistry of the surface cuticle of the protonymphs mimics that of the ant larvae (see Hölldobler \& Wilson 1990).

The pseudoscorpions that associate with ants are often capable of surviving in close proximity to both large numbers of workers and the nests. The compressed body of pseudoscorpions may allow them to retreat into narrow crevices that are inaccessible to the ants. However, it is not known whether the pseudoscorpions evade attack from ants entirely by their secretive behavior, or whether they also employ some form of chemical mimicry or defense.

\section{ACKNOWLEDGMENTS}

We thank Steve Shattuck and Catriona McPhee for identifying the ants; James Jessup, Greg Dalton and Rachel Allan for their help in the field; Robin Wilson for providing accommodation; and the Australian Research Council (A19331563) for financial support.

\section{REFERENCES}

Elgar, M. A. 1993. Inter-specific associations involving spiders. Mem. Qld. Mus. 33:411-430.

Harvey, M.S. 1988. The systematics and biology of pseudoscorpions. Pages 75-86 in: Austin, A. D. and Heather, N. W. (eds). Australian Arachnology. Australian Entomological Miscellaneous Publication \# 5, Brisbane, Australia. 
Harvey, M.S. 1991. Catalogue of the Pseudoscorpionida. Manchester University Press: Manchester.

Harvey, M.S. 1992. A new genus of myrmecophilous Chernetidae from southern Australia (Pseudoscorpionida). Rec. West. Aust. Mus. 15:763-775.

Hölldobler, B. and Wilson, E. O. 1990. The Ants. Harvard University Press, Cambridge, Massachusetts.

Jeffries, M. J. and Lawton, J. H. 1984. Enemy free space and the structure of ecological communities. Biol. J. Linn. Soc. 23:269-286.

Kistner, D. H. 1979. Social and evolutionary significance of social insect symbionts. Pages 339-413 in: Hermann, H. R. (ed). Social Insects Volume 1. Academic Press, New York.

Kistner, D. H. 1982. The social insects' bestiary. Pages 1-224 in: Hermann, H. R. (ed). Social Insects Volume 3. Academic Press, New York.

Mahnert, V. 1985. Weitere Pseudoskorpione (Arachnidae) aus dem zentralen Amazonasgebiet (Brasilien). Amazoniana 9:215-241.

Pierce, N. E. 1987. The evolution and biogeography of associations between lycaenid butterflies and ants. Oxford Surveys Evol. Biol. 4:89-116.

Shattuck, S. O. 1992. Review of the dolichoderine ant genus Iridomyrmex Mayr with descriptions of three new genera (Hymenoptera: Formicidae). J. Aust. ent. Soc. 31:13-18.

Weygoldt, P. 1969. The Biology of Pseudoscorpions. Harvard University Press, Cambridge, Massachusetts.

Zeh, J. A. and Zeh, D. W. 1990. Cooperative foraging for large prey by Paratemnus elongatus. J. Arachnol. 18:307-312. 

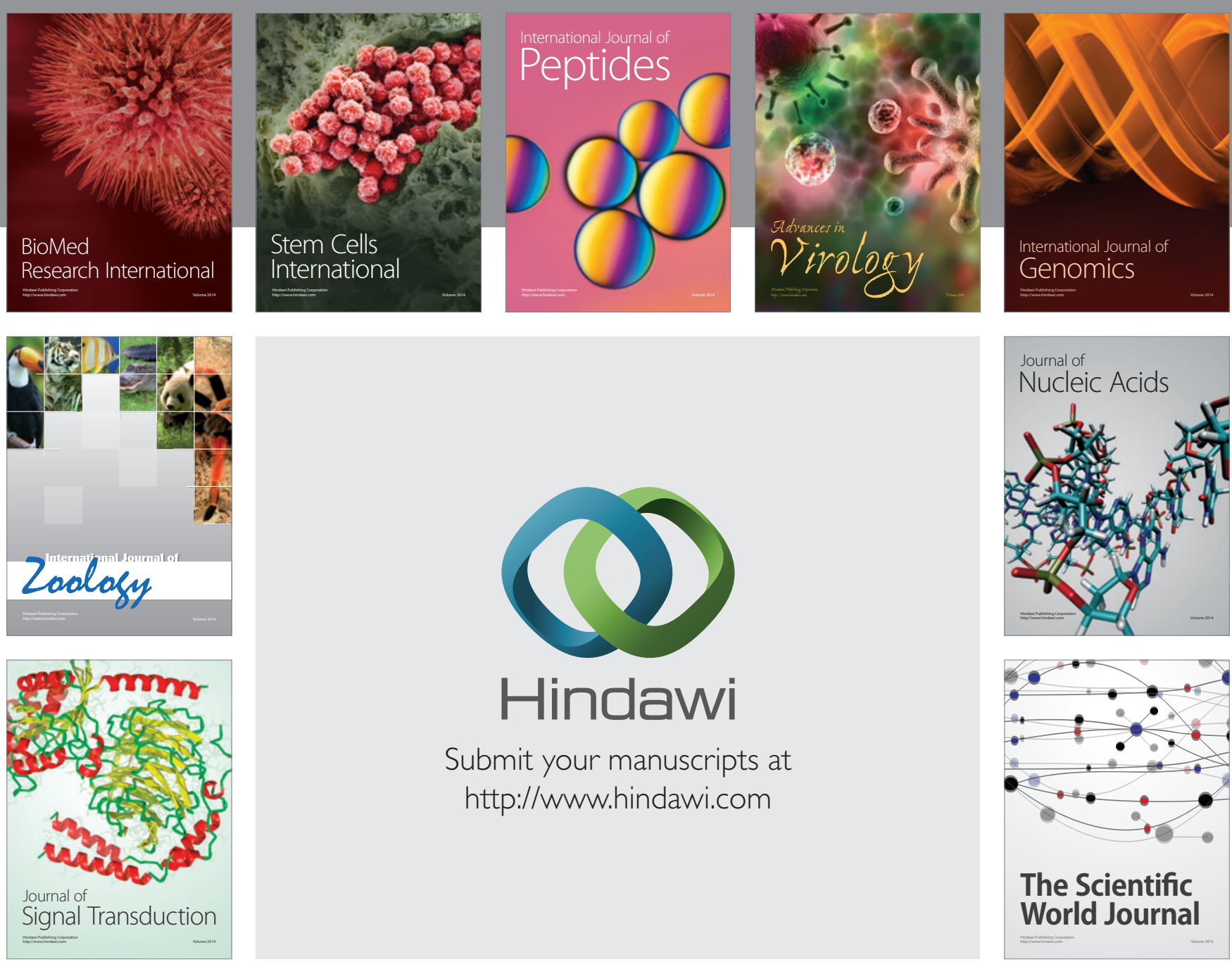

Submit your manuscripts at

http://www.hindawi.com
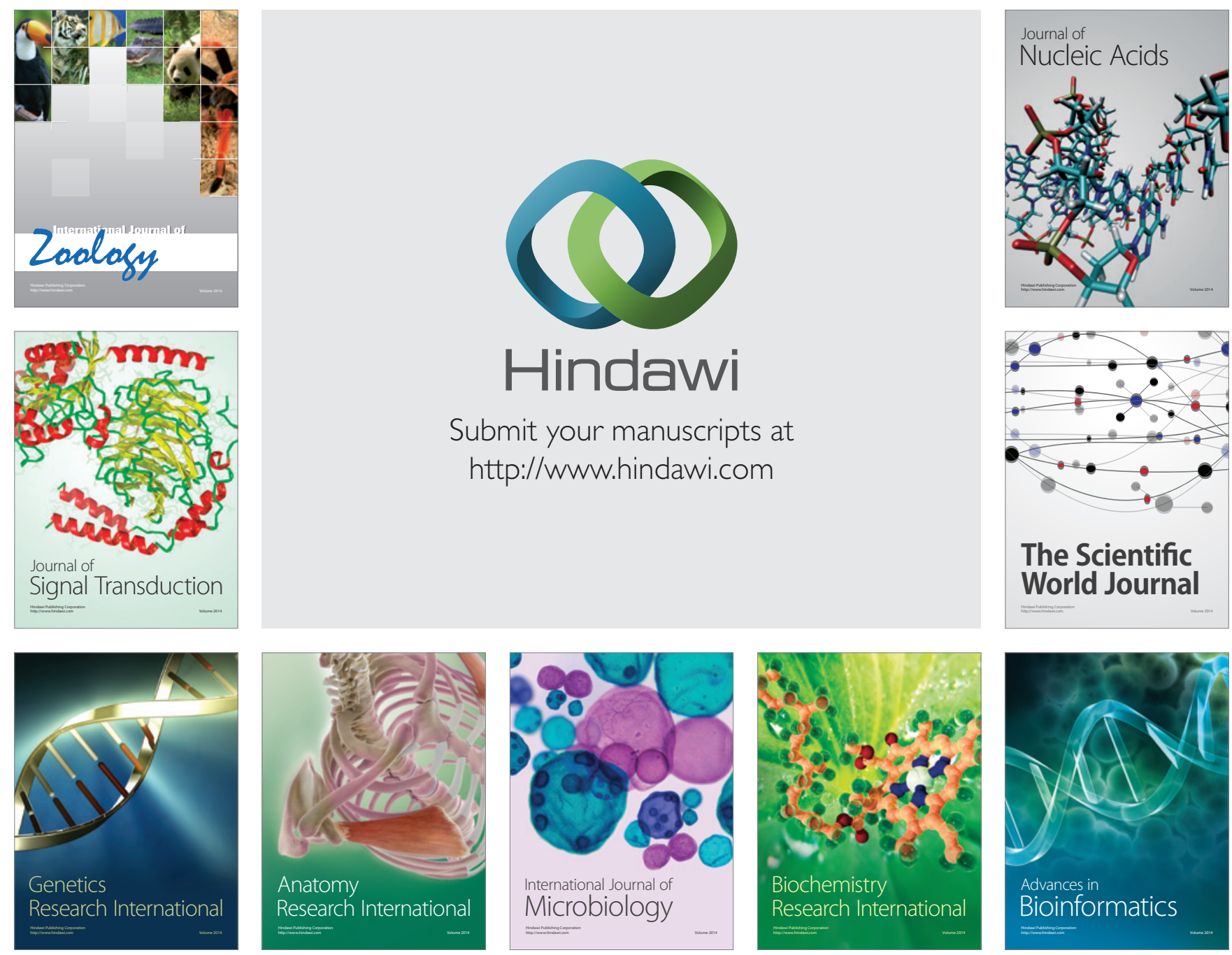

The Scientific World Journal
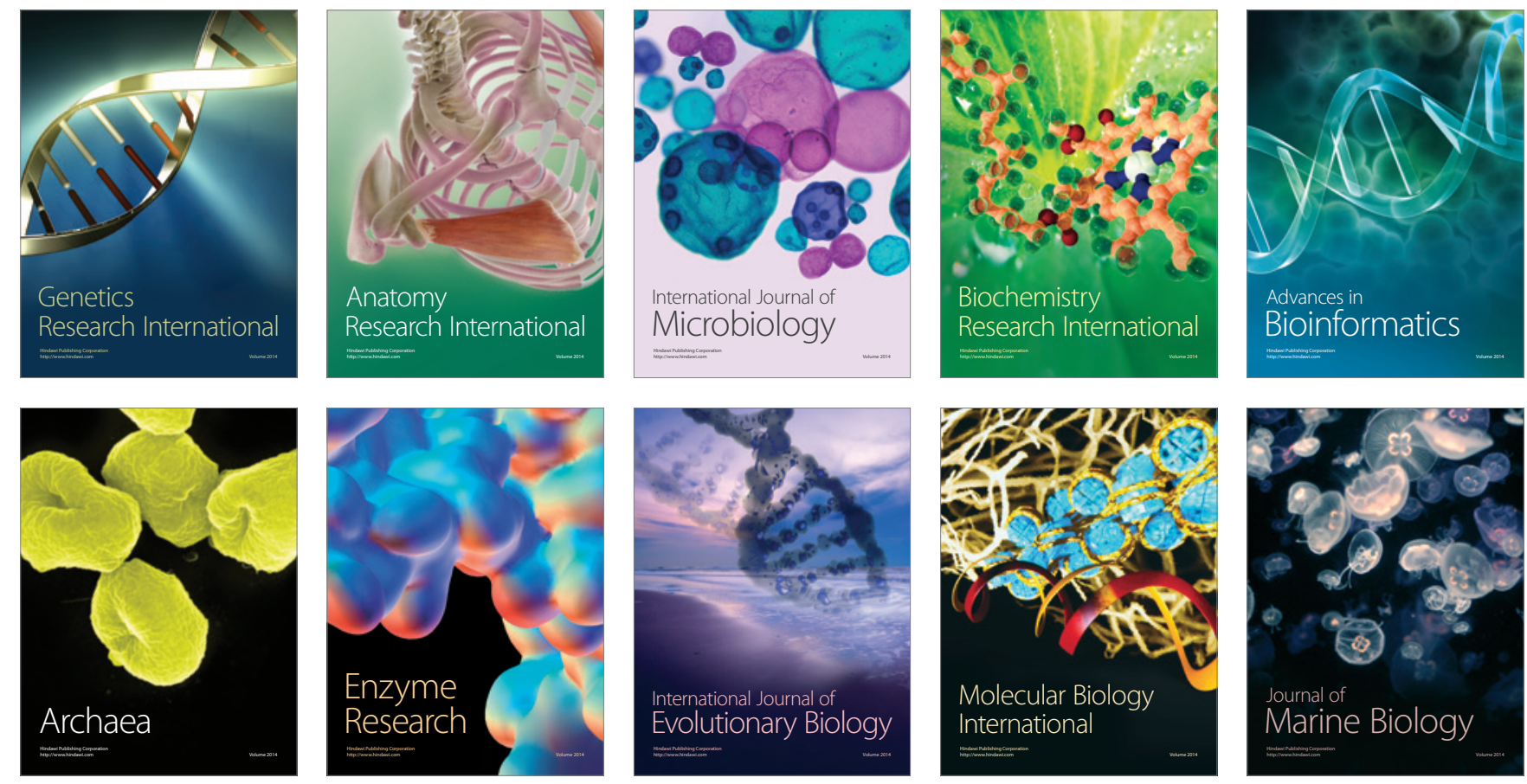